A gaseous inhibitor is not inconsistent with the above facts, and it is suggested that failure to germinate is due either to a lack of oxygen, or to a build-up of carbon dioxide concentration having a narcotic effect, within the immediate region of the germinating embryo.

A more detailed report of this and other experiments will appear elsewhere.

Welsh Plant Breeding Station,

P. B. Vose

University College of Wales,

Aberystwyth.

July 25.

\section{Differences in Social Aggregation in Two Species of Locust}

Natural populations of locusts are characterized by large fluctuations in numbers, accompanied by changes in morphology, colour and behaviour in both the nymphs (hoppers) and the adults. When numbers are high, the hoppers aggregate into bands containing from a few hundred to several thousand individuals. Similar gregarious hoppers can be produced in the laboratory by rearing several together in one cage ${ }^{1}$. There is much circumstantial evidence to suggest that, provided the total numbers are sufficient, the formation of hopper bands depends partly on a patchy physical environment, especially a vegetation mosaic, and partly on strong attractions between hoppers ${ }^{2,3}$

In the laboratory, the hopper inter-attractions leading to aggregation have been studied in cages that provide a physically uniform environment". In recent experiments, groups of ten hoppers were tested in an evenly lighted and heated, ring-shaped cage, the floor of which was marked radially into twenty equal divisions. When first placed in the cage, the ten hoppers moved about; but later they settled down, those in the same division generally touching one another. After $30 \mathrm{~min}$. the number in each division was noted. The hoppers were then disturbed so that the groups were broken up, and after another 30-min. period the number in each division was again noted. Four such readings constituted a test. No hopper group was subjected to more than one test per day.

If the hoppers settled at random, the number of cage divisions containing $0,1,2,3$, and so on, would follow a binomial distribution given by the formula $(19 / 20 \times 1 / 20)^{10}$. The percentage of hoppers grouped (that is, in groups of two or more) would be 37.5 , and in each test of four readings, involving 80 divisions, 48 divisions would be empty, 25 would contain one hopper and 7 would contain two or more. If more hoppers were grouped than one would expect for random distribution, then the grouping was due to the hoppers being attracted to one another, since the cage provided a physically uniform environment and the hoppers moved actively before coming to rest. Such grouping has been called social aggregation. In successive tests, any differences in the amount of grouping was a measure of the difference in strength of hopper inter-attractions.

Two locust species, Locusta migratoria migratorioides (R. and F.) and Schistocerca gregaria (Forsk.), were compared. They came from the routine stocks of the Anti-Locust Research Centre that have been kept crowded in cages for many generations. Small batches of hoppers (six batches of locusta and seven of Schistocerca) were tested soon after hatching and at intervals of one or two days afterwards until the
Table 1. The Average NUMber of Divisions containing $0,1,2$, 3 OR MORE HOPPERS
(The figures are based on $3-5$ separate tests, each test consisting of

\begin{tabular}{|c|c|c|c|c|c|c|c|c|c|c|}
\hline \multirow{3}{*}{$\begin{array}{l}\text { Age from } \\
\text { hatching }\end{array}$} & \multicolumn{5}{|c|}{ Locusta } & \multicolumn{5}{|c|}{ Schistocerca } \\
\hline & \multicolumn{4}{|c|}{$\begin{array}{l}\text { No. of hoppers } \\
\text { per division }\end{array}$} & \multirow{2}{*}{$P^{*}$} & \multicolumn{4}{|c|}{$\begin{array}{l}\text { No, of hoppers } \\
\text { per division }\end{array}$} & \multirow{2}{*}{$P^{*}$} \\
\hline & 0 & 1 & 2 & $\begin{array}{c}3 \circ \mathrm{r} \\
\text { more }\end{array}$ & & 0 & 1 & 2 & $\begin{array}{l}3 \text { or } \\
\text { more }\end{array}$ & \\
\hline Up to & & & & & & & & & & \\
\hline 6-12 hr. & $\begin{array}{l}47 \\
53\end{array}$ & 19 & $\begin{array}{l}5 \\
6\end{array}$ & $\begin{array}{l}1 \\
2\end{array}$ & $>0.3$ & $\begin{array}{l}02 \\
55\end{array}$ & $\begin{array}{l}21 \\
15\end{array}$ & $\begin{array}{l}4 \\
6\end{array}$ & $\begin{array}{l}3 \\
4\end{array}$ & $\begin{array}{l}>0.5 \\
<0.05\end{array}$ \\
\hline 1 day & 52 & 20 & 6 & 2 & $>0 \cdot 3$ & 58 & 13 & 4 & 5 & $<0.02$ \\
\hline 2 days & 55 & 16 & 4 & 5 & $>0.05$ & 58 & 12 & 6 & 4 & $<0.01$ \\
\hline 3 days & 58 & 12 & 5 & 5 & $<0.01$ & 59 & 13 & 2 & 6 & $<0.02$ \\
\hline $\begin{array}{l}4 \text { days } \\
5 \text { days }\end{array}$ & 58 & 13 & 5 & 4 & $<0.02$ & 58 & 13 & $\overline{4}$ & 5 & $<0.02$ \\
\hline $\begin{array}{c}\text { (near to } \\
\text { moulting) }\end{array}$ & 55 & 15 & 6 & 4 & $<0.05$ & 55 & 15 & 6 & 4 & $<0.05$ \\
\hline
\end{tabular}

end of the first instar. The tests were carried out at an air temperature of $28^{\circ} \mathrm{C}$. and the hoppers were well fed before each test, these physical conditions having been found to be optimal for social aggregation in both species ${ }^{4}, 5$.

Soon after hatching and the intermediate moult, when the cuticle was still a little soft, the hoppers of both species distributed themselves at random within the cage (Table 1). About six hours after hatching, the Schistocerca hoppers showed strong attractions for one another and their distribution was probably not a chance one. One day after hatching, Schistocerca showed maximum social aggregation and the hopper distribution differed significantly from chance. This contrasted strongly with the behaviour of the Locusta hoppers, which continued to settle at random until they were two or three days old, maximum aggregation not occurring until they were three or more days old.

The hatching of hoppers of swarming populations of Schistocerca has often been observed in the field. The hoppers of each egg pod usually hatch within a few minutes of one another ${ }^{2}$ and the number from a single pod is generally between 40 and 90 . Conse. quently, the hoppers begin their life by being grouped. For the first five or six hours after hatching they are very inactive and remain grouped around the egg-pod holes. If they are undisturbed, very little movement takes place during the first day. The laboratory experiments suggest that one day of grouping is sufficient for the hoppers to learn to aggregate and so to resist factors leading to dispersal. No corresponding field observations have yet been made with hatchlings of swarming populations of Locusta, but the specific difference in social aggregation demonstrated in the laboratory suggests that under natural conditions hatchlings of Locusta are more easily dispersed than those of Schistocerca. It also seems likely that a patchy physical environment is of greater importance in the retention of groups and the formation of new ones in Locusta than in Schistocerca.

I wish to thank Prof. G. C. Varley for laboratory facilities in the Hope Department, Oxford.

\section{Peggy E. Ellis}

Anti-Locust Research Centre,

London.

Ang. 17.

${ }^{2}$ Faure, J. C., Bull. Ent. Res., 23, 293 (1932).

2 Ellis, P. E., and Ashall, C., Anti-Locust Bull. No. 25 (in the press).

${ }^{3}$ Davey, J. T., and Johnston, H. B., Anti-Locust Bull. No. 22 (1956).

4 Ellis, P. E., Behaviour, 5, 225 (1953).

${ }^{5}$ Ellis, P. E. (unpublished laboratory data). 